\title{
The Life and Times of Lilian Lee: An Analysis of Lee's Screenplays From Psychological and Stylistic Perspectives
}

\author{
Weixiao Zhang ${ }^{1}$ \\ ${ }^{1}$ Communication University of China School of Theater Film and Television, Beijing, China \\ Correspondence: Weixiao Zhang, Communication University of China, Dingfuzhuang Road, Chaoyang District, \\ Beijing, China. Tel: 86-156-6696-5858.
}

Received: February 2, 2020

Accepted: March 24, 2020

Online Published: March 25, 2020

doi:10.20849/ajsss.v5i1.728

URL: https://doi.org/10.20849/ajsss.v5i1.728

\begin{abstract}
Lilian Lee, a novelist and screenwriter, is a prominent figure in the Hong Kong film industry and literary circles. Her unique writing style has earned her wide acclaim. Most of her works feature romances, fantasies or mysteries, showing her creative imagination. However, she didn't let love stories and supernatural elements overshadow the full picture she depicted. Instead, she further explored themes such as gender identity, sexual orientation and feminism, and dug deeper into a broad range of topics including mortality, fatality, history and patriotism. She revealed the complexity of human nature and the inner conflicts her characters underwent through incisive remarks and heart-rending stories. Her best-known works include Farewell My Concubine, Green Snake, Rouge and Kawashima Yoshiko, all of which are considered masterpieces, representing a milestone in the history of Asian cinema. Farewell My Concubine remains the only Chinese-language film to win both the Palme d'Or at the Cannes Film Festival and the Golden Globe Award for Best Foreign Language Film. It was included in Time's list of "All-Time" 100 Movies in 2005. Rouge had 16 nominations and awards at the Hong Kong Film Awards and the Taipei Golden Horse Film Festival. It also earned Lee the Hong Kong Film Award for Best Screenplay. The critical and commercial success of these films is largely attributed to Lee's screenwriting, and the success of her screenwriting rests on her relatively fixed writing mindset. This article focuses on screenplays written by Lilian Lee and analyzes her construction of plot, narrative techniques and her writing mindset and style, by exploring the influence of her personal experience, aesthetic preference, writing habits, and her cultural, social and educational background on her works.
\end{abstract}

Keywords: Lilian Lee, writing mindset, aesthetic preference, Peking opera, characterization, female screenwriters

\section{Introduction}

Lilian Lee, also known as Lee Pik-Wah in Hong Kong, is a prolific female screenwriter who has developed a unique style of writing and made remarkable achievements. This article aims to explore her writing mindset and style. As Friedländer explained, art is a product of the mind, and therefore any research on art must be related to psychology (1946). To study how Lee has achieved excellence in screenwriting, it is necessary to have a thorough understanding of her experience, aesthetic preference and writing habits, and analyze her writing mindset as well as style.

Although Lee's novels won enormous popularity as early as in the 1980s, it was not until the mid-1990s that they started to receive scholarly attention. Initially, some scholars classified her works as popular culture that cater to popular taste. Gradually, they realized the cultural phenomena behind Lee's success were complicated and began to study her works from multiple perspectives. These existing studies on Lee's writing generally fall into four categories. The first one is textual analysis. The majority of them are case studies of one of Lee's works, and some of them also cover topics such as Hong Kong literature and Chinese-language cinema (Li, 1991; Tang, 2005). The second category contains studies from the perspectives of narratology and aesthetics. Some focus on Lee's style of writing, including her retelling of classic stories, use of supernatural elements and narrative in historical settings (Chen, 2002); others explore motifs and political metaphors in Lee's writings (K. Wang, 2014). The third category is comparative analysis, with many comparing Lee with other Hong Kong female writers such as Eileen Chang (Yin, 2008). The fourth type of study analyzes Lee's works with new methodologies from multiple perspectives which are not confined to literary theories, including psychology, post-colonialism and 
women's studies. This study will take the fourth approach to further examine Lee's works.

This article is divided into three parts. The first part examines the influence of Lee's personal experience on her writing, including how she, as a native of Hong Kong, was affected by the collective consciousness and sense of disorientation of Hong Kong people. The second part focuses on Lee's aesthetic preference, and analyzes her frequent use of elements of traditional Chinese culture, especially those related to Peking opera. The third part points out the similarities and differences among the characters portrayed by Lee, which reveal her writing mindset. By studying all these aspects in detail, this article explains Lee's writing style, writing mindset and how she made her way to a successful screenwriter.

\section{The Influence of Lee's Experience on Her Works}

\subsection{Early Years and a Need for Self-Fulfilment}

Lilian Lee was born into a wealthy family of traditional Chinese medicine practitioners, which enabled her to have an access to decent education, acquire a sound knowledge of mythologies and anecdotes, and enter a Western-style school when she was older. However, it was still a large family with conventional views and a strict hierarchy. Men were allowed to have more than one wife, and it was common to see family members conspire against each other. Due to the family atmosphere, Lee, on the one hand, gained worldly wisdom and drew much of her inspiration for her later works from her childhood experience, but on the other, understood the dark side of human nature at an early age and got into the habit of satirizing and criticizing hypocrites, traitors, cowards, and people showing blind loyalty or filial piety, in a harsh and bitter way. This is also why almost all her characters have the bad habits which were considered deeply entrenched in Chinese culture. She wanted to reveal the truth about human nature and sober those who indulged in merry-making. Even her stories featuring ghosts and evil spirits were designed as allegories of human society.

Lee is a reserved, gifted writer but is considered plain in appearance, which makes her, to some degree, similar to Lin Daiyu in Dream of the Red Chamber, and lack feminine charm in the eyes of some conventional Chinese men. She had a painful experience of unrequited love which she found hard to get over. This explains why she has a preference for writing stories about a woman being infatuated with a heartless, cowardly man. Her female characters are brave and steadfast in their romantic relationships, which makes them stand out in a social environment where other women remain passive and submissive. These characters usually awaken to the importance of independence and feminist consciousness when their relationships fail. Some end up in a situation similar to that of Medea in Euripides's tragedy, while others become awakened and independent like Nora in Ibsen's A Doll's House. According to the "peak experience" theory developed by Maslow, Lee transferred her emotions onto her characters to find comfort from the stories she wrote (1976). As her characters discover the truth about love and life, Lee herself fulfils her dream through them. She unconsciously created her ideal self in her works, and reached the level of "transcendence" in the hierarchy of needs through her honourable female characters. However, this was not enough. If she had only focused on personal satisfaction, her literary achievements would have been stuck at the level of popular culture. Instead, her aim was to provide hope for all women. To encourage them to "enjoy the moment with your beloved, no matter how good or bad the ending is" was only a way to provoke thought and develop empathy between herself and her female audience. (Note 1) Lee's ideal life extends well beyond this: she seeks complete fulfilment, 70 percent materially and the rest 30 percent spiritually; she wants to live with high quality, work with half of her energy, and love with her pure lust (Zhan, 2007). This is an exaggeratedly humorous way to encourage her audience to bravely recognize their nature and the needs of their inner self. Because of the influence of traditional Chinese culture, people were too afraid to talk openly about their lust and relationships, but Lee aimed to inspire her audience to free themselves from the shackles and live life to the full. Only when her audience achieve a higher level of consciousness beyond her works, can Lee gain complete fulfilment as a writer.

\subsection{The Collective Consciousness and Common Disorientation Among Hongkongers}

Lilian Lee was born and raised in Hong Kong, and her sense of identity as a Hong Kong local has dominated her self-awareness. During the period of British rule, the city was in an awkward position between submissiveness and resistance, the East and the West, tradition and modernity, as well as conservatism and open-mindedness. As Hong Kong transformed from a small fishing village into the world's most prosperous port city, its residents developed a unique "Hong Kong ideology".

As the day set for Hong Kong's return to China drew near, many long-standing problems could no longer be ignored and Hong Kong people started to feel lost, which created a paradox: on the one hand, they had an increasing identification with the Chinese nation, but on the other, they remained disdainful of mainland culture. This weakened their shared sense of superiority. Anxious and disorientated, they asked themselves repeatedly 
who they are, how to define Hong Kong, and How to define China.

In the 1980s, when Lilian Lee was at the height of her creative power, the collective consciousness and prevalent sense of disorientation among Hong Kong people began to be reflected in literary works at that time, which shared certain similarities. The focus shifted from depicting the city's own culture to narrating the historical connection between Hong Kong and the mainland. Many works were based on traditional Chinese culture, some adapting folklore and others featuring anecdote and urban mysteries. Writers often made adjustments to classic stories according to their own understanding as Hong Kong locals, regardless of what these stories originally focused on. They showed a strong desire in their writing to participate in the process of enriching Chinese culture and to leave their mark in the history of Chinese art as Hongkongers. Tang points out that "the most conspicuous feature of Lilian Lee's writing is its Hong Kong characteristics, giving it a touch of complexity and mystery, which makes her works retain serious themes while suit popular taste" (2005: 11). For instance, the film Rouge (1988) written by Lee tells the doomed romance of Fleur, whose ghost returns to the living world to look for her lost lover. Her story is entwined with changes in Hong Kong society and reveals different generations of Hongkongers' different attitudes towards love and relationships: in the past, romantic relationships were male-dominated and many ended up with the couple committing suicide to be together in death, as depicted in the famous folktale The Butterfly Lovers (also known as Liang Shanbo and Zhu Yingtai in China), while in modern society, more emphasis is laid on gender equality and individuality, which enables couples to have a kind, clean breakup. In Rouge, the attitude of the young couple (Yuen and Chor) in modern Hong Kong towards the relationship between Fleur and Chan Chen-Pang also change markedly, from envy and compassion, to aversion, and finally to awe and respect. Their changing attitude is reminiscent of the ebbs and flows of Hongkongers' sense of belonging to China and their general lack of a sense of cultural identity. During that period, the colonial government overseen by the British government focused on economic growth, kept a tight rein on ideology and restricted the development of serious Chinese literature, making Hong Kong literary works generally entertaining and commercial. Nonetheless, Lee was trying hard to make her voice heard through her works as a female screenwriter and a Hongkonger.

\section{Lee's Aesthetic Preference: Chinese Opera and Traditional Culture}

A writer's aesthetic preference has an enormous influence on his or her writing mindset. Lilian Lee is an atheist but is intensely curious about myths and folktales, and therefore she wrote many ghost stories reflecting harsh realities of human society.

Traditional Chinese opera is an element that appears in almost all of Lee's screenplays. She often stresses in her works the theme that "all the world's a stage, and all the men and women merely players". In these Chinese opera-related stories written by Lee, characters either turn a fake romance into a real one, or cannot distinguish their emotion in acting from that in real life. The former situation may lead to a happy ending, but the latter is doomed to be tragic. Both of the situations smack of a sense of mystery and fatalism. It echoes Chinese people's "theatre superstition", which means people believe that theatre gives predictions and warnings about real life.

In Green Snake, quotes from Chinese opera libretti are used in the conversations between White Snake and Hsui Xien when the couple pledge their love for each other and when they sound each other out on the Dragon Boat Festival. The form resembles that of Western opera but has an extra trace of reserve and shyness which is typical in Eastern culture. The two events in the film also echo the familiar stories in traditional Chinese opera of love at first sight and a husband having suspicion about his wife.

In Rouge, Chan Chen-Pang was impressed by and attracted to Fleur because of her clever use of quotes from Chinese opera libretti when they first met. Chinese opera was a crucial part in their tug-of-war of love and influenced the development of their relationship.

In Farewell My Concubine, Cheng Dieyi is an opera-maniac. He loses himself in getting into character and cannot distinguish his real self from Consort Yu, the role he plays. Despite the popular prejudice against this art form, he gains a deep sense of honour from his vocation as a Peking opera actor. The person he adores most is Duan Xiaolou, another actor who plays Xiang Yu, echoing Consort Yu's affection for Xiang Yu in the play. He thinks art goes beyond national boundaries. Therefore he appreciates the Japanese general who has a thorough knowledge of opera and vehemently opposes the reform of Chinese opera during the Cultural Revolution, even if it may lead to his personal disaster. However, Lee also brought her misunderstanding of history into her work. In the novel Farewell My Concubine, Lee's depiction of the Cultural Revolution is too thin and the story ends with Cheng Dieyi fleeing to Hong Kong and starting a family there, which seems unrealistic. This results from Lee's lack of knowledge of Beijing and the political disturbance in mainland China. She was unable to accurately reproduce the damaging impact of the political movement on traditional Chinese opera, the Chinese art industry 
and the minds of ordinary Chinese people. Fortunately, Chen Kaige, the director who adapted the novel into a film, has strong feelings about the Cultural Revolution because of his painful experience during that period, which enabled him to help Lee polish her screenplay. J. Wang observes that the plot of Dieyi's suicide in Lee's original novel is only the character's imagination, which downplays the conflict between Dieyi's unusual life and social reality, and fails to create an unexpected turn for the audience. However, Mr. Chen Kaige's adaptation is more daring and has a stronger emotional impact on the audience (2019).

To Lee, traditional Chinese opera is the crown jewel of Chinese culture. The philosophy of life and the blurred distinction between illusion and reality demonstrated in this art form have fascinated her, which led to her frequent use of opera elements in her works.

\section{The Pattern of Lee's Characterization and Her Writing Mindset}

According to the "mirror stage" theory of Jacques Lacan, humans spend their whole life in an endless quest for their true self (1979). However, the Ego can never be found, because it is replaced by the Other, the ideal self people pursue, when they see their own image in the mirror for the first time. The gap between the Ego and the Other can never be bridged, which leads to humans' never-ending confusion and struggle. The characters created by Lee usually suffer the confusion regarding who they really are due to certain dramatic events in their life, which is "the core of the play" that brings a story to a climax.

\subsection{The Struggle for a Sense of Gender Identity}

Carl Jung invented the concept of anima and animus to explain his idea that women have an unconscious masculine side and men have an unconscious feminine side, to which Lilian Lee also subscribes to (1966).

In Rouge, Fleur often dresses up as a man, which makes her attractive to Chan Chen-Pang who has certain feminine traits. The two people both show traits of the opposite sex, which makes them complementary to each other, achieving a balance of masculinity and femininity. The film Green Snake is based on a Chinese folktale Madame White Snake. In the initial version of the story, Green Snake used to be a male who adored White Snake, but was reincarnated as a female to accompany her when he found out White Snake was in love with another man. Similarly, in the film Green Snake, Green Snake is possessive of White Snake, which goes beyond mere sisterhood. To find out whether White Snake cares about her, Green Snake takes a risk to seduce Hsui Xien, White Snake's husband, who is hesitant and endowed with feminine features. This is another example of the interesting and typical combination of characters with shifted gender identity.

In her later works, Lee dug deeper into the topic of gender identity, and treated it as a root cause of her characters' personal tragedy. In Farewell My Concubine, Cheng Dieyi has had a weak personality since he was a child. To teach him to play Dan roles (female roles in Chinese opera), he was raised as a girl by his master. Moreover, he grew up in the opera troupe together with Duan Xiaolou, who is considerate, reliable and more masculine, which made him doubt his gender identity and sexual orientation at an early age. Later, when practicing the play Dreaming of the World outside the Nunnery, he asked himself the serious question about his identity, gender and fate, "Am I by nature a boy or a girl", by using a line of the play.

As a Qian Dan (a man playing female roles in Peking opera), Cheng Dieyi enjoys considerable fame but does not receive respect. If he is a man by nature, why does he need to suffer sexual assault by a male aristocrat and sacrifice sexually in exchange for the safety of his beloved? Xing also explores Cheng Dieyi's mentality from psychological and anthropological perspectives, and points out that he could have accepted his male identity, but wavered because of Juxian's involvement in his relationship with Duan Xiaolou, which coincides with this article's ideas (2002). If he is a woman by nature, why Xiaolou is so scared of his love, and why is he stigmatized as a traitor to China and a prostitute, though he has acted Consort Yu's part brilliantly and has devoted his whole life to art. Lee created this character in order to show her audience the fragility and suffering of Qian Dan actors behind their breathtakingly beautiful acting. They were destined to face a personal tragedy whether they chose to be a man or a woman, because in traditional Chinese society, people considered unusual were not granted freedom to seek self-fulfilment or love, which reveals the inhumanity and tragedy of the times.

\subsection{The Blurring of National Identity: China, Hong Kong and Japan}

As pointed out in previous chapters, Lilian Lee is an expert in depicting Hongkongers' struggle for a sense of national identity and Chinese opera actors' struggle for a sense of gender identity. In the film Kawashima Yoshiko, the two types of struggle are interwoven. Kawashima Yoshiko was a princess of the Qing dynasty but became a traitor to China and served as a spy for the Japanese army. Her life of notoriety was a tragedy of the violent times she lived in and of her blurred national as well as gender identity. In the film, when Yoshiko was given up for adoption to a Japanese man, she sobbed "I'm Chinese", but in the end when she was on trial for treason, she 
shouted "I'm Japanese" to claim innocence. Growing up in the fight for power between different sides, Yoshiko was taught to live and strive for rebuilding Manchuria, and was exploited by patriarchy and the so-called noble cause of rebuilding the country. She was raped by her adoptive father and forced to marry a stranger in exchange for power for others, naively believing it was a heroic sacrifice. When she realized women would always be ignored and sacrificed in East Asian society, she abandoned her female identity and started to live like a male. With a male-like aggressive way of working, she gained power, influenced politics and hoped to use Japan's military advantage to restore the imperial family of Qing dynasty to power, but all her attempts ended in abject failure. She was deserted by her country and condemned by her compatriots, because she was deceived by the concept of the so-called Greater East Asian Co-Prosperity Sphere, deviated from her initial goal, and tried to regenerate the Chinese nation in a way she thought effective. She and Fook, a staunch patriot, loved each other, but drifted apart due to their different aspirations, which shows the audience Yoshiko's blurred national identity and dangerous obsession. No matter how she defended herself, there is no doubt that she tried to fulfil her so-called aspiration, which turned out to be a delusion, by harming her fellow countrymen and her motherland. Lilian Lee's vivid portrayal explains Kawashima Yoshiko's mentality and psychological motivation for her wrongdoing.

Kawashima Yoshiko's mixed feelings about China resonated with Hongkongers' attitude towards China when the day of Hong Kong's return was approaching, which was a combination of a sense of belonging and disappointment about being abandoned. Yang observes that the tragedy of the then British-colonized Hong Kong was like the tragedy of an abused woman (2019). Yoshiko and that generation of Hongkongers all grew up under foreign rule, Japanese and British respectively; they all wanted to lead the rapid development of China but failed due to their distorted perception of values, national identity and history. Instead of contributing to the well-being of Chinese people, Yoshiko harmed her compatriots, which led to her personal disaster. Lilian Lee retold the story of Kawashima Yoshiko in a critical but sympathetic way. As a Hong Kong local, Lee was able to empathize with Yoshiko, and thus explored the topic of blurred national identity in a way loyal to her true feelings but not political correctness.

\subsection{The Id and the Superego: The Blurred Distinctions Between Human and Spiritual Beings in Love and Lust}

Apart from the struggle for a sense of gender and national identity, Lee also explored other aspects of human mind and returned to the fundamental question of philosophy: who am I? Lee's works of fantasy featuring supernatural elements often reveal the conflict between the id, ego and superego, and between morality and hedonism. By writing these myths about love and lust, Lee created harmony between herself and the hidden side of her personality. Sigmund Freud pointed out that art is a substitute for sexual satisfaction (1977). When writing about love and lust, Lee didn't avoid talking about how her characters were driven by their sexual instincts, and treated all kinds of love equally, including homosexual relationships, human-ghost relationships, human-demon relationships, age-gap relationships and interfaith relationships. In her depiction of love, Lee blurred the distinctions between humans and supernatural beings, and explored the grey area between the id and superego.

Lee's thought on the distinctions between human and supernatural beings is best reflected in the film Green Snake. Instead of focusing on White Snake, Lee told the story from the perspective of a supporting role Green Snake, who does not have a high aim, and gave the mischievous, less experienced snake spirit an opportunity to feel the joys and sorrows of life in the human world. Therefore, she cannot empathize with White Snake's pursuit of being a human and never suppresses her own desires as a demon. Her childlike and animal-like mentality is well reflected in her unspoken thoughts in a sword fight scene between Green snake and White snake in Lee's original novel: "Stab! Blood, sweet and sour and cold, will be like a bowl of plum juice, flooding the bed" (1995: 122). Growing and learning in the human world like a new-born child, Green Snake experiences imitation, confusion, enlightenment and finally self-fulfilment. According to Freud's psychoanalysis theories, when Green Snake behaves like a demon, indulges her desires and follows her animal instincts, she is completely id-ridden, but to behave like a human requires her to observe legal and moral rules, put others before herself, hold back her emotions, and even hide her identity as a demon. The flooding in the temple near the end of the film marks Green Snake's most heroic moment, when she recognizes her responsibility and sacrifices herself after witnessing White Snake's self-sacrifice. At that moment, her id loses dominance, and her ego mediates between her id and superego, which leads to her act of self-sacrifice. However, by doing so, she maximizes the value of her effort and highlights the importance of love and respect, which makes her sacrifice meaningful and worthwhile. She crosses the boundary between humans and demons when she understands the meaning of love and sacrifice. In contrast, Fat-hoi, though a symbol of authority and morality, fails to distinguish between right and wrong, pledges to eliminate all evil spirits and obdurately hunts demons. He ignores and suppresses humans' natural desires, and consequently causes horrible tragedies. By doing so, he can never achieve enlightenment in 
Buddhism and is even not good enough to be called a human. The story shows that demons with human qualities are lovable, while humans without human qualities are pathetic. Lee's skilful depiction draws her level with her two predecessors Pu Songling and Eileen Chang, both prominent figures in the history of Chinese literature. All three of them are experts in fantasy and masters of satire. Xu notes that Chang and Lee's attention to and recognition of nontraditional romantic relationships demonstrate their more tolerant attitude towards different lifestyles and more liberal feminist ideas (2019). Lee loathes rules and norms, but sticks to her own principles, which include respecting human nature. This is also reflected in her writing and guides her choice when developing characters.

\section{Conclusion}

By analyzing the general style of Lilian Lee's works, this article has explored her writing mindset and preference. As has been shown, her writings reflect the collective consciousness and a shared sense of disorientation of Hong Kong people, display her aesthetic preference for traditional Chinese culture and Peking opera, and demonstrate her adherence to her principles, all highlighting her distinctive style. Lee's works suit both refined and popular taste and find a balance between serious literature and popular culture, covering a wide range of topics from people's conflicts with others and their inner self, to the struggle for one's national and gender identity, with a touch of melancholy and compassion. Meanwhile, many of her stories have a happy ending to lighten the mood of her audience, which enables her to maintain a balance between commercial interest and artistic merit. She sticks to her motto of "being master of my own writing instead of subjecting to others". Although she often wrote stories of doomed romance full of horror and sorrow, she shared her thoughts with her audience on mortality, fatality, history and patriotism through her aureate style of writing, and encouraged them to express their true self and keep pursuing their dreams even if they are in inner conflict as are her characters.

\section{Acknowledgements}

My greatest thanks go to Professor Li Shengli and Associate Professor Huang Jinhua (Communication University of China) for their invaluable suggestions. I would also like to thank Li Jiaying for her research assistance.

\section{References}

Chen, X. (2002). Zhengdian de mingyun - Shilun Li Bihua xiaoshuo gaixie chuantong de fangshi [The destiny of classics - An analysis of Lilian Lee's way of retelling classic stories]. Jiangxi Shehui Kexue, 02, 35-38.

Freud, S. (1977). Introductory Lectures on Psychoanalysis (J. Strachey, Trans.). New York: W. W. Norton \& Company.

Friedländer, M. J. (1946). On Art and Connoisseurship. Oxford: Bruno Cassirer.

Jung, C. G. (1966/1981). Two Essays on Analytical Psychology (R. F. C. Hull, Trans.). London: Routledge \& Kegan Paul.

Lacan, J. (1979). The Four Fundamental Concepts of Psycho-Analysis (A. Sheridan, Trans.). Harmondsworth: Penguin.

Lee, L. (1995). Qing She [Green snake]. Beijing: Renmin wenxue chubanshe.

Li, C. (1991). Mingzi de gushi - Li Bihua Yanzhikou wenben fenxi [What's in a name - A textual analysis of Lilian Lee's Rouge]. In B. Chen (Ed), Xianggang wenxue tanshang [Exploration and appreciation of Hong Kong literature] (pp. 296-304). Hong Kong: Sanlian Shudian.

Maslow, A. H. (1976). The Farther Reaches of Human Nature. New York: Penguin.

Tang, L. (2005). Xianggang chengshi jingshen guanzhao xia de jingzhi - Lun 1980, 90 niandai Li Bihua de xiaoshuo chuangzuo [Landscape with the spirit of the city of Hong Kong - An analysis of Lilian Lee's novel writing in the 1980s and 1990s]. Unpublished doctoral dissertation, Fudan University, Shanghai, China.

Wang, J. (2019). Li Bihua xiaoshuo de guaidan mei jiqi dianying gaibian [The beauty of eeriness in Lilian Lee's novels and their film adaptations]. Dangdai Dianying, 11, 111-115.

Wang, K. (2014). 1980 niandai yilai Pan Jinlian muti liubian yanjiu [Changes in the motif of Pan Jinlian since the 1980s]. Unpublished master's thesis, Bohai University, Jinzhou, China.

Xing, B. (2002). Zhenshi de huanjue - lun bawang bieji zhong de "anima" yuanxing [Real illusions - "Anima" roles in Farewell My Concubine]. Sheke Zongheng, 5, 57-58+60.

Xu, B. (2019). Zhang Ailing yu Li Bihua xiaoshuo aiqing, shengming guan zhi bijiao [A comparative analysis of 
views on love and life in Eileen Chang's and Lilian Lee's novels]. Yanbian Jiaoyu Xueyuan Xuebao, 33(02), $18-20+24$.

Yang, S. (2019). Xianggang dianying de nvxing shenti xiuci [The figurative use of women's body image in Hong Kong films]. Wenhua Yishu Yanjiu, 12(03), 108-113.

Yin, X. (2008). Li Bihua yu Zhang Ailing chuyi [Lilian Lee and Eileen Chang]. Shidai Wenxue, 05, 12-13.

Zhan, Y. (2007, August). Cainv Li Bihua, Bulaoerhuo de hunyin lan po [Lilian Lee: A well-educated lady and a lazy woman in marriage]. Xiandai Nvxing, 9-11.

\section{Note}

Note 1. This was an advertising slogan of the film Green Snake and was included in the lyrics of its theme song.

\section{Copyrights}

Copyright for this article is retained by the author(s), with first publication rights granted to the journal.

This is an open-access article distributed under the terms and conditions of the Creative Commons Attribution license (http://creativecommons.org/licenses/by/4.0/). 